УДК 82-6

DOI: $10.17223 / 24099554 / 9 / 2$

\title{
Е.А. Вишнякова
}

\section{ИНОЯЗЫЧНЫЕ ВКРАПЛЕНИЯ В ПЕРЕПИСКЕ В.А. ЖУКОВСКОГО И А.П. ЕЛАГИНОЙ ${ }^{1}$}

Статья посвящена изучению мультилингвизма русской словесной культуры ХІХ в.; исследуется роль немецких, латинских, английских и итальянских иноязычных вкраплений как формы литературного многоязычия в переписке В.А. Жуковского и А.П. Елагиной. Делается вывод о том, что важнейшую функииональную нагрузку в их эпистолярном диалоге принимает на себя немецкий язык, формирующий значимые для жизнетворчества собеседников концепты, связанные с семьей, дружбой, эстетическими и бьтийно-философскими категориями романтизма.

Ключевые слова: иноязычные вкрапления, эпистолярий, В.А. Жуковский, А.П. Елагина, литературный мультилингвизм, языковая личность.

Переписка В.А. Жуковского и А.П. Елагиной представляет собой репрезентативный памятник словесной культуры России. Письма двух корреспондентов, по словам Э.М. Жиляковой, «являются ценнейшим документом истории русской философской, эстетической, педагогической и общественной мысли» [1. С. 662]. Корпус писем В.А. Жуковского и А.П. Елагиной насчитывает 394 текста 18131852 гг. Наибольшую часть иноязычного текста в переписке составляют французские фрагменты, что обусловлено феноменом диглоссии в русском образованном обществе. С одной стороны, эти включения не выполняют той функции, которая характерна для иноязычных вкраплений (ИВ) в понимаемом нами смысле, поэтому французский язык переписки не входит в спектр нашего исследования. С другой стороны, русско-французской диглоссии XIX в. посвящен целый ряд работ [2-5], в том числе и ее специфике у Жуковского [6, 7]. В то же время переписка Жуковского с Елагиной содержит ИВ на немецком (70),

\footnotetext{
${ }^{1}$ Исследование выполнено при финансовой поддержке РФФИ в рамках научного проекта № 18-312-00050.
} 
английском (3), итальянском (2) и латинском (19) языках, что дает основание толковать их как значимые в плане поэтики и эстетики жанра дружеского литературного письма.

Актуальность изучения многоязычия в эпистолярном дискурсе русских классиков определяется возрастающим в отечественной и зарубежной науке о литературе интересом к различным аспектам взаимодействия языков в тексте. Методологической базой для данной статьи являются работы в области мультилингвизма томской филологической школы жуковсковедения [6-10].

Говоря о владении языками обоих коммуникантов, нужно заметить, что Жуковский великолепно знал французский, немецкий, итальянский, английский и латинский языки; Елагина получила замечательное домашнее образование. Ее обучением занимались наставницы-француженки, немецкому языку и литературе ее учили особые педагоги, а также сам Жуковский, который определял круг чтения, переводов и характер занятий. Елагина владела английским и итальянским языками и выполняла с них переводы, среди которых «ДонКихот» Ж.-П. Флориана, рыцарская повесть из «Sagen der Vorzeit» $Ф$. Вебера, отрывки из мемуаров Х. Стеффенса, «Левана, или О воспитании» Ж.-П. Рихтера, «Жизнь Гусса» Ф. Боншоза, «Тысяча одна ночь», «Принцесса Брамбилла» Э.Т.А. Гофмана [11. С. 487]. Интерес к многоязычию отразился и в ее культурно-общественной деятельности. Так, с именем Елагиной связан один из самых известных литературных салонов XIX в.: «Приезжавшие в Москву знаменитости, русские и иностранные, являлись в салон Елагиной» [12. С. 204].

В переписке Жуковского и Елагиной особый интерес представляют обращения к немецкому языку. Немецкие вкрапления акцентируют значимые для жизнетворчества обоих собеседников концепты, связанные с семьей и дружбой, бытийно-философскими категориями и эстетикой романтизма, и становятся своего рода прецедентными текстами, складываются в целостный коммуникативный код эпистолярного диалога.

Особо насыщен немецкими вкраплениями самый драматичный период переписки, связанный с надеждой Жуковского на союз с М.А. Протасовой, которому Елагина всячески способствовала. Бытийные концепты и интеретексты немецкой литературы обретают устойчивый ореол смыслов, становясь компонентами особой семиосферы жизнетворчества круга Жуковского. Так, Елагина 22 апреля 1815 г. 
пишет: «<..> вы говорите, что расставание - хорошее дело, потому что оно сближает? Да, если брать в товарищи Einfalt und Wahrheit» [13. С. 62] (нем. «простоту и правду»). В этом же письме она цитирует К.М. Виланда: «Ein einziger Augenblick kann alles umgestalten!!» (нем. «Одно мгновение может все переменить»). Эту цитату Жуковский использовал в дерптских письмах-дневниках, обращаясь к М.А. Протасовой. Известно, что Елагина была знакома с дневником, а потому использовала цитату в качестве прецедентного текста. Однако прагматика высказывания Жуковского и Елагиной различна. Если в цитате поэта прослеживается надежда на счастливое соединение с возлюбленной, то племянница добавляет новый смысл. Она задается вопросами нравственного толка: можно ли в мгновение изменить хорошее, великость души и твердость.

Воспоминания о Марии Протасовой красной нитью проходят в диалоге Жуковского и Елагиной. В новогоднее письмо к наступающему 1831 г. поэт включает отрывки из писем М.А. Протасовой к К. фон Зейдлицу, в которых она, предчувствуя скорую кончину, размышляет о своей жизни и дает наставления по-немецки. Использование немецкого языка в эпистолярии обусловлено несколькими факторами. Во-первых, Зейдлиц писал на родном языке, во-вторых, образовательная среда Императорского Дерптского университета, в котором преподавание велось на немецком языке, имела влияние и на коммуникацию в самом городе. Однако немецкий язык в эпистолярном диалоге Зейдлица с М.А. Протасовой и Жуковским имел не просто формальный статус: по замечанию Н.Е. Никоновой, в данном случае «обращение к адресату на родном языке означает, среди прочего, доверие и искренность пишущего» [14. С. 25]. В ответ на письмо Жуковского от 1 января 1831 г. Елагина также делится воспоминаниями о Маше, но переводит фокус на ее дочь Катю и просит, чтобы ее передали ей на воспитание: «Mы с вами бы поделились: - Die Mutter ist alt und schwach, die Tochter ist klein und schwach» [13. С. 359] (нем. «Мать стара и слаба, дочь мала и слаба»). В детях Елагина видит утешение и надежду на будущее. Так, в конце октября 1822 г. она советует Жуковскому прекратить горькие воспоминания: «Мильй друг, прошедшее без будущего никуда не годится! < .. > Маша возвратила мне на минуту и то, и другое: но моя участь не дала мне и ее присутствием вполне насладиться» [Там же. С. 246]. 
Елагина приходилась Жуковскому племянницей и была его преданным другом и соратницей. Оба «принадлежали к одному типу людей той духовной культуры, где определяющей была проблема нравственного поведения и гармонического развития личности» [1. С. 636]. Семейно-дружеский союз В.А. Жуковского, М.А. Протасовой и A.П. Елагиной в письмах обозначается словом «Kleeblatt» (нем. «лист клевера», «трилистник») в переносном значении («неразлучная тройка»). Впервые это вкрапление появляется в конце письма от 4 декабря 1815 г.: «Kleeblat noch ein mal» [13. С. 143] (нем. «и вновь трилистник») как знак дружбы и признательности; завершает композицию письма клятвенное изречение, обращенное к Жуковскому «Selbst im Tod» (нем. «Даже в смерти»).

Обсуждение горестных для семьи событий зачастую сопровождается переключением на немецкий язык, употреблением понятий-маркеров, символизирующих ценностные ориентиры и дорогие сердцу воспоминания и смыслы, которые призваны быть утешением в настоящем. Эмблема «Kleeblatt» вновь возникает как ассоциация, связанная с трагическими событиями 1829 г.: смертью Александры Воейковой и болезнью двух Екатерин, Мойер и Воейковой. В письмо к Елагиной Жуковский включает два фрагмента посланий К. Зейдлица о последних днях жизни и похоронах Александры Воейковой, написанных по-немецки. 3 апреля 1829 г. Елагина в ответ на это письмо говорит о себе: «Бедный третий листок нашего Kleeblatta! < .. > На что одна так отчуждена! Должна засыхать даже после их могиль!» [Там же. С. 331]. Еще через десять лет, 12 апреля 1839 г., Елагина просила Жуковского приехать к ней и передать ей «на мытарство» Е. Мойер и Е. Воейкову, поскольку «обе стали не совсем здоровы $<$... >; все горячо меня полюбили и не догадались сначала, что это оттого, что я (третий листок нашего Kleeblatt) берегу в себе души их матерей» [Там же. C. 448]. Так немецкое вкрапление «Kleeblatt» выполняет функцию ценностной самоидентификации, обозначает духовный союз, в воспоминании о котором авторы писем находят душекрепительные силы.

Дочь М.А. Протасовой, Е.И. Мойер, получила прозвище «Schneewittchen» (нем. «Снегурочка»). По признанию самой Е.И. Мойер, так называл ее А.П. Протасов, «потому что помнил, что ребенком я была очень бела» [15. С. 278]. Так ее называют и Жуковский, и Елагина. Подобные прозвища в духе арзамасской галиматьи являются 
типичными для эго-дискурса Жуковского, игровой и одновременно кодовый компонент их семантики подчеркивается благодаря использованию иностранного языка. Например, в путешествии по Германии в 1832 г. поэт нанял себе осла и дал ему ироническую кличку «Blondchen» (досл. «блондинчик»): «< ..> осел, которого я нанял на все время моего пребывания в Эмсе; зовут его Blondchen (белокурый)» [16]. Кроме того, сын Жуковского Павел получает шутливое прозвище «Herr Ochs» (нем. «Господин бык»). Об этом поэт пишет 13 октября 1845 г. А.О. Смирновой: «А Павел Васильевич так богатырски толст, что уже проименован мною: Herr Ochs» [17]. При этом сам Жуковский подписывается «Бык І».

ИВ в переписке Жуковского и Елагиной репрезентируют контекст философско-эстетической традиции романтизма. Послания включают в себя важнейшие ее концепты, связанные с эстетикой чувствительности, как-то: «Неimweh» (нем. «тоска по родине») и «Sehnsucht» (нем. «страстное желание», «томление»). Понятие «Неimweh» возникло, как известно, в швейцарском диалекте в XVII в. как медицинский термин, обозначавший болезнь, тоску о родине, ностальгию. В эпоху романтизма оно было переосмыслено, прежде всего, в романах И.Г. Юнг-Штиллинга («Das Heimweh», 1794-1796) и У. фон Залиса «Картинная галерея больных тоской по родине» («Bildergallerie der Heimweh-Kranke», 1800).

В переписке Жуковского и Елагиной концепт «Неimweh» служит реализации мотива «милого края». Так, например, 11 июня 1815 г. поэт пишет из Санкт-Петербурга: «Знаете, что всякий ясный день, всякий запах березы производит во мне род Неітwеh, так же, как и всякая красная кровля, покрытая черепицами, поневоле тащит все воображение туда, куда и хотеть не должно» [13. С. 87]. Елагина 25 декабря 1835 г., будучи вдали от дома, пишет: «Колокола на моей соседке Kreuzkirche таким праздничным звоном оглушают с пяти часов утра весь дом наш, что не знаешь, куда уйти от непобедимого Heimweh, который они назвонили» [Там же. С. 420].

Мотив тоски по родине также реализуется через упоминание музыкальных произведений: увертюр и антрактов Филоктета, созданных А.А. Плещеевым. Так, 26 июня 1815 г. Елагина пишет: «Есть какой-то постоянно повторяемый, который кажется национальною песнию Отечества Филоктета и который точно дает какой-то Heimweh обо всем, что любит» [13. С. 99]. Обращение к конститутивному 
в эстетике немецкого романтизма понятию позволяет актуализировать в живой коммуникации образ, получивший индивидуальное художественное измерение в литературном общении поэта и провиденциальное значение для его творческой биографии.

Схожее место в исследуемом корпусе эпистолярных текстов занимает философия «Sehnsucht» / «томления», инспирированная важнейшей для эпохи романтизма теологической и философской концепцией, обозначавшей сердечное желание и стремление души, которому не суждено осуществиться; «это сильное желание чего-то ценного в сочетании с чувством печали, чего невозможно достичь, может быть связано с прошедшим и потерянным, или с будущим и надеждой» $[18]$.

«Sehnsucht» фигурирует в письмах Елагиной, «томление» выражает как скорбь по ушедшим, так и желание скорой встречи. 7 мая 1831 г. она пишет: «Сегодня во сне видела вас; видела всех, кого уже не увижу, с такою полною радостью свидания, с таким совершенным забвением всех горестей разлук, что иелое утро не могу отвязаться oт такого томительного Sehnsucht, какое тяжелее всех воспоминаний» [13. С. 361]. Четыре месяца спустя она, сетуя на невозможность встречи, снова апеллирует к романтическому понятию: «Неужели вы на 28 дней не можете приехать ко мне? - Неужели весь мой Sehnsucht перенести в будущую жизнь?» [Там же. С. 366]. И, наконец, еще через три месяца «Sehnsucht» выражает одиночество: «< ...> только сына Царского, Пробудителя нету тут: а с этим нету, Бог знает, сколько связано лишения, u Sehnsucht, и одиночества» [Там же. С. 371], что, думается, вызвано переживанием трудностей, возникших у сына Елагиной Ивана Киреевского с изданием журнала «Европеец» и управлением расстроеным имением.

Так, восходящее к немецкому романтизму понятие «Sehnsucht» связано в письмах Елагиной с личностью Жуковского, относится в равной степени к общему прошлому, сопрягаясь с «философией воспоминания» о безвременно ушедших «милых спутниках» М.А. Протасовой-Мойер и А.А. Воейковой, и к будущему, в котором живет надежда на долгожданную встречу с поэтом. Идентификация этого концепта с фигурой Жуковского отчасти подтверждается и тем, что в немецком языке «Sehnsucht» относится к женскому роду, тогда как Елагина употребляет его в мужском роде: «томительного Sehnsucht», «мой Sehnsucht». Такая интерференция связана не только со звуковой 
оболочкой, напоминающей звучание русского слова, принадлежащего к мужскому роду.

Иноязычные вкрапления представляют собой продуктивный элемент эпистолярия русских классиков; немецкий язык в их диалоге становится конститутивным для формирования семиосферы жизнетворчества Жуковского, которое Елагина улавливает и акцентирует в своих письмах. Немецких вкраплений в письмах Елагиной больше, чем в посланиях Жуковского, но художественные стратегии использования этих вкраплений являются общими для обоих адресатов и отражают главные образы лирики поэта, инкорпорированные в русскую литературу благодаря его германофильству.

Елагина реализует разнообразные лингвистические стратегии при оформлении немецких вкраплений. По классификации Ю.Т. Листровой-Правды, эти вкрапления принадлежат к контаминированному типу, т.е. функционируют по словообразовательным и синтаксическим законам русского языка. К ним следует отнести, к примеру, вкрапления в косвенном падеже с добавлением русского окончания «Kutscher`a», «Schillera». Русско-немецкий литературный билингвизм Елагиной проявляется гармонично на синтаксическом уровне в согласовании членов предложения: «мне нужно, чтобы вы dann und wann протягивали ко мне губы с дружбою» [13. С. 210] (нем. «время от времени»), «всякое горе, всякое страдание готова теперь перенести mit Grossherzigkeit» [Там же. С. 169] (нем. «с великодушием»), «должна была взять карету с условием останавливаться nach Belieben» [Там же. С. 409] (нем. «по требованию»).

Функциональная значимость немецких вкраплений в философскоэстетическом и жизнетворческом смыслах понимается в сопоставлении с латинскими вкраплениями, которые в переписке фигурируют чаще всего в типичной для них утилитарной роли: в основном это сокращения NB (8), PS (5), sic (2), служащие для разграничения текста и привлечения внимания адресата к важному смысловому фрагменту. B письмах Жуковского находятся восклицание «Vivat», выполняющее экспрессивную функцию, и крылатое выражение «status quo» (лат. «равновесие»), когда речь заходит о сватовстве В.К. Ржевского к Е.И. Мойер: «...не советую продолжать с ним никакого по этому предмету сношения; пусть все останется in status quо» [13. C. 478]. На этом фоне выделяется, пожалуй, наличествующее у обоих корреспондентов словосочетание «terra incognita» (лат. «неизвестная 
земля»). Для Елагиной «terra incognita»- это деревня Юшковых Игнатьево: «Игнатьево, то есть маленький костел в обетованной земле, о котором некоторые листки говорят, будто она terra incognita!» [13. С. 125]; для Жуковского «terra incognita» ассоциируется с Долбино, когда «свет лежал вдали, как terra incognita...» [Там же. С. 364]. Крылатое выражение служит для художественной маркировки образов пространства и времени, которые имели особое значение для обоих литераторов; переключение на латынь в данном случае позволяет придать сакральный оттенок упомянутым хронотопам.

Известно, что Елагина внесла значительный вклад в развитие русской педагогической мысли. Педагогический дискурс в переписке маркируют английские вкрапления. 12 апреля 1839 г. она сообщает Жуковскому о намерении создать коллекцию сочинений о воспитании, в которую среди прочих должны войти сочинения английских педагогов Марии Эджворт (Maria Edgeworth, 1767-1849) и Елизаветы Гамильтон (Elizabeth Hamilton, 1756-1816), фамилии которых пишутся в оригинале.

В письме от 28 декабря 1843 г. Елагина описывает свое переживание по поводу переезда Жуковского с супругой во Франкфурт: «I was well, would be bellow ${ }^{2}$ took physick and died» [Там же. С. 514] (англ. «Я чувствовала себя хорошо, если бы было лучше, я бы приняла лекарство и умерла»). Эту цитату можно найти в «Полном английсконемецком словаре» Н. Бэйли («А Compleat English Dictionary: Oder Vollständiges Englisch-Deutsches Wörterbuch», 1788) в качестве примера употребления слова «Physick». Находился ли словарь в библиотеке Елагиной - неизвестно. Вероятнее всего, она использует прецедентный текст, чтобы сообщить о своем здоровье, но не для придания ему самоценного художественного осмысления, как в случае с немецкими вкраплениями. В предыдущем письме она информирует Жуковского о своем состоянии по-русски: «Я всю зиму, друг мой, была больна; жестоко больна, едва могла пройти по комнате < .. >» [Там же. С. 512]. В иных случаях английский язык в эпистолярном корпусе не появляется, что свидетельствует об ограниченной сфере его употребления в коммуникативном пространстве адресатов, появление этих ИВ связано, скорее, с занятиями и кругом чтения Елагиной.

\footnotetext{
${ }^{2}$ Вероятно, опечатка. Должно быть «better». - E.B.
} 
В то же время итальянский язык мы встречаем исключительно в письмах Жуковского к Елагиной. Поэт использует инсулоним Isola Bella и концепт «far niente» (итал. «ничегонеделение») в связи с путешествием в Италию. Обещая поделиться описанием путешествия, позднее, в июне 1822 г., он пишет: «Анете отдайте лавровую ветку, которую я сорвал для нее на Isola bella под прекраснылм небом Италии» [13. С. 237]. В дневниках Жуковского инсулонимы Isola Bella и Isola Madre сохраняются в исходном написании во время трех заграничных путешествий и формируют образ Италии в восприятии автора.

Итальянский концепт «far niente» обретает в письмах Жуковского иной смысл, связанный с имагологическим горизонтом русской литературы (его можно встретить в «Евгении Онегине», «Стансах Толстому» А.С. Пушкина, «Ницце» П.А. Вяземского, «Dolce far niente» В.Я. Брюсова, в эпистолярии К.Н. Батюшкова и Н.В. Гоголя). Считается, что это выражение восходит к письму Плиния Младшего либо речи Цицерона. В русской культуре XIX в. «far niente» понималось как «досуг, свобода, противопоставленная необходимости заботиться о “материальных нуждах", суетности мира, это внутренний покой, отсутствие амбициозных стремлений, наслаждение красотой южной природы, иногда состояние созерцательности и душевного равновесия» [19. С. 44]. В эпистолярном общении Жуковского и Елагиной «far niente» связан с образом невесты Елизаветой Рейтерн и обретает позитивное значение. Из письма от 28 августа 1840 г.: «И так и потонешь в этом невыразимом famiente счастия, которое все меня обхватило» [13. С. 467]. В других письмах Жуковского концепт «far niente» обретает негативную коннотацию в связи с неудачной беременностью Елизаветы Жуковской, а также с болезнью глаз самого поэта [20. С. 430].

Дальнейшее изучение ИВ как формы литературного полилингвизма в эпистолярном дискурсе русских классиков является продуктивным с точки зрения поэтики дружеского письма и расширения представлений о языковой биографии авторов и литературном быте эпохи. В связи с подготовкой коллективом Томской школы жуковсковедения завершающих шести томов писем в составе «Полного собрания сочинений и писем» Жуковского обретает актуальность исследование ИВ в эпистолярии дружеского круга первого русского романтика. 


\section{Лuтература}

1. Жилякова Э.М. Переписка А.П. Елагиной и В.А. Жуковского как памятник русской культуры первой половины XIX века // Переписка В.А. Жуковского и А.П. Елагиной. 1813-1852. М. : Языки славянской культуры, 2009. С. 633-665.

2. Лотман Ю.М. Русская литература на французском языке // Русская литература на французском языке XVIII-XIX веков / вступ. статья, биограф. очерки и коммент. Ю.М. Лотмана и В.Ю. Розенцвейга. Wien : Biblion Media GmbH, 1994. С. 103-127. (Wiener slawistischer Almanach. Sonderband 36).

3. Гречаная Е.П. Когда Россия говорила по-французски: русская литература на французском языке (XVIII - первая половина XIX века). М. : ИМЛИ РАН, 2010. 383 с.

4. French and Russian in Imperial Russia / ed. by D. Offord, L. Ryazanova-Clarke, V. Rjéoutski, G. Argent. Edinburgh : Edinburgh University Press, 2015. Vol. 1. 270 p.; Vol. 2. $266 \mathrm{p}$.

5. Паперно И.А. О двуязычной переписке пушкинской эпохи // Ученые записки Тартуского университета. Труды по русской и славянской филологии. Тарту, 1975. Вып. XXIV. C. 148-156.

6. Вяткина И.А. Диглоссия русских маргинальных жанров (домашняя поэзия и эпистолярий В.А. Жуковского) : автореф. дис. ... канд. филол. наук. Томск, 2007. 23 с.

7. Вяткина И.А., Лебедева О.Б. Диглоссия эпистолярия В.А. Жуковского // Вестник Томского государственного университета. 2007. № 294. С. 7-10.

8. Лебедева О.Б., Янушкевич А.С. Германия в зеркале русской словесной культуры XIX - начала XX века. Кельн ; Веймар ; Вена : Bohlau Verlag, 2000. 274 c.

9. Никонова Н.Е. В.А. Жуковский и немецкий мир. М. ; СПб. : Альянс-Архео, 2015. $496 \mathrm{c}$.

10. Поплавская И.А. Русско-итальянское двуязычие в дневниках В.А. Жуковского 1820-1830-х гг. // Вестник Томского государственного университета. 2011. № 350. C. 21-28.

11. Бартенев П.И. Авдотья Петровна Елагина // Русский архив. 1877. № 8. С. 483-495.

12. Аронсон М., Рейсер С. Литературные кружки и салоны. М. : Аграф, 2001. 400 с.

13. Переписка В.А. Жуковского и А.П. Елагиной. 1813-1852 / сост., подг. текста и коммент. Э.М. Жиляковой. М. : Языки славянской культуры, 2009. 729 с.

14. Никонова Н.Е. Переписка В.А. Жуковского и К.К. Зейдлица: русско-немецкий диалог // Вестник Томского государственного университета. 2010. № 330. С. $20-27$.

15. Елагина Е.И. Семейная хроника // Российский архив: история Отечества в свидетельствах и документах XVIII-XX вв. : альманах. М. : Студия ТРИТЭ; Российский архив, 2005. Вып. 14. С. 271-323.

16. Письмо В.А. Жуковского к великому князю Александру Николаевичу // РГАЛИ. Ф. 198. Оп. 1. № 51.

17. Письмо В.А. Жуковского к А.О. Смирновой // РО ИРЛИ. № 21216 (собр. Бартенева).

18. Kirchner C.M. Wörterbuch der Philosophischen Grundbegriffe. Leipzig: Verlag der Dürr'schen Buchhandlung, 1907. 559 s. URL: http://www.textlog.de/2061.html

19. Сиднева C.A. Репрезентация концепта dolce far niente в русской лингвокультуре // Вестник Московского университета. Сер. 19, Лингвистика и межкультурная коммуникация. 2014. № 4. С. 38-47. 
20. Письмо В.А Жуковского к А.М. Тургеневу // Русская старина. 1885. T. XLVIII. C. $428-431$.

\section{FOREIGN INCLUSIONS IN THE CORRESPONDENCE OF VASILY ZHUKOVSKY AND AVDOTIA ELAGINA}

Imagologiya i komparativistika - Imagology and Comparative Studies, 2018, 9, pp. 1729. DOI: $10.17223 / 24099554 / 9 / 2$

Yekaterina A. Vishniakova, Tomsk State University (Tomsk, Russian Federation). E-mail: ekaterina.vishniakova@mail.ru

Keywords: foreign inclusions, epistle, Vasily Zhukovsky, Avdotia Elagina, literary multilingualism, linguistic identity.

The reported study was supported by the Russian Foundation for Basic Research (Project № 18-312-00050).

The paper studies the nineteenth-century Russian literary multilingualism, which has never been given scholarly attention before. The author analyses the role of German, Latin, English and Italian inclusions as a form of literary multilingualism in the correspondence of Vasily Zhukovsky and Avdotia Elagina. The German language represents concepts of family, friendship, existential philosophical categories and aesthetics of romanticism, which were important in the life of both correspondents and organized coherent communicative code of their epistolary dialogue. The discussion of the sorrowful family events often switches into German, which symbolizes axiological orientations, recollections and meanings that counterbalance their real experience. The epistolary dialogue between Zhukovsky and Elagina should be considered in the broader context of the Romanticism literary tradition. The correspondence includes the most important concepts of German Romanticism related to aesthetics of sensitivity "Heimweh" and "Sehnsucht." "Heimweh" serves to realise the motive of "native land." The address to this constitutive concept makes alive the image that received an individual artistic perception in the poet's literary dialogue and became providential for his creative biography. "Sehnsucht" in Elagina's letters is connected with Zhukovsky's personality and equally refers to their common past, related to the "philosophy of recollection" of the dearly departed Maria Protasova-Moyer and Aleksandra Voeikova, as well as future, in which Elagina hopes to meet the poet. German becomes constitutive for the formation of Zhukovsky's creative semiosphere, which Elagina captures and develops in her letters. She uses more German inclusions in her letters than Zhukovsky, which is evident of her own strategy. However, there are common artistic strategies for their use of inclusions, too. These strategies reflect the main images and poetisms of Zhukovsky`s poetry incorporated into Russian literature due to his Germanophilism. Latin inclusions in the correspondence perform a typically utilitarian role, represented by abbreviations NB, PS and sic. They are used to mark the text and attract attention of the addressee to an important semantic fragment. The winged phrase "terra incognita" gives a sacred hue to the meaningful chronotopes. In its turn, English is significant in Elagina's educational system. She uses it to translate her feelings, however its use is limited by her personal reading scope. Italian can be found in Zhukovsky's letters as well. 
The poet fixes the island names Isola Bella and Isola Madre in Italian graphics. They form the image of Italy in the perception of Zhukovsky-traveler, The concept of "far niente" is associated with the image of Elizabeth von Reutern.

\section{References}

1. Zhilyakova, E.M. (2009) Perepiska A.P. Yelaginoy i V.A. Zhukovskogo kak pamyatnik russkoy kul'tury pervoy poloviny XIX veka [Correspondence between A.P. Elagina and V.A. Zhukovsky as a monument of Russian culture of the first half of the 19th century]. In: Zhukovsky, V.A. \& Elagina A.P. Perepiska V.A. Zhukovskogo i A.P. Yelaginoy. 1813-1852 [Correspondence between V.A. Zhukovsky and A.P. Elagina. 1813-1852]. Moscow: Yazyki slavyanskoy kul'tury. pp. 633-665.

2. Lotman, Yu.M. (1994) Russkaya literatura na frantsuzskom yazyke [Russian Literature in French]. In: Lotman, Yu.M. \& Rozentsveyg, V.Yu. Russkaya literatura na frantsuzskom yazyke: frantsuzskie teksty russkikh pisateley XVIII-XIX vekov [Russian Literature in French: French Texts of Russian Writers of the 18th-19th Centuries]. Vienna: Biblion Media GmbH. pp. 103-127.

3. Grechanaya, E.P. (2010) Kogda Rossiya govorila po-frantsuzski: russkaya literatura na frantsuzskom yazyke (XVIII - pervaya polovina XIX veka) [When Russia spoke French: Russian literature in French (the 18th - first half of the 19th centuries)]. Moscow: The Gorky Institute of World Literature, RAS.

4. Offord, D., Ryazanova-Clarke, L., Rjéoutski, V. \& Argent, G. (2015) French and Russian in Imperial Russia. Vol. 1. Edinburgh: Edinburgh University Press.

5. Paperno, I.A. (1975) O dvuyazychnoy perepiske pushkinskoy epokhi [On the bilingual correspondence of the Pushkin era]. Uchenye zapiski Tartuskogo universiteta. Trudy po russkoy i slavyanskoy filologii. 24. pp. 148-156.

6. Vyatkina, I.A. (2007) Diglossiya russkikh marginal'nykh zhanrov (domashnyaya poeziya i epistolyariy V.A. Zhukovskogo) [Diglossia of Russian marginal genres (home poetry and epistolary of V.A. Zhukovsky)]. Abstract of Philology Cand. Diss. Tomsk.

7. Vyatkina, I.A. \& Lebedeva, O.B. (2007) Bilinguism of epistolary heritage of V.A. Zhukovsky. Vestnik Tomskogo gosudarstvennogo universiteta - Tomsk State University Journal. 294. pp. 7-10. (In Russian).

8. Lebedeva, O.B. \& Yanushkevich, A.S. (2000) Germaniya v zerkale russkoy slovesnoy kul'tury XIX - nachala XX veka [Germany in the mirror of Russian verbal culture of the 19th early 20th centuries]. Cologne, Weimar, Vienna: Bohlau Verlag.

9. Nikonova, N.E. (2015) V.A. Zhukovskiy i nemetskiy mir [V.A. Zhukovsky and the German World]. Moscow; St. Petersburg: Al'yans-Arkheo.

10. Poplavskaya, I.A. (2011) Russian-Italian bilingualism in V.A. Zhukovsky's diaries of 1820s-1830s. Vestnik Tomskogo gosudarstvennogo universiteta - Tomsk State University Journal. 350. pp. 21-28. (In Russian).

11. Bartenev, P.I. (1877) Avdot'ya Petrovna Yelagina [Avdotya Petrovna Elagina]. Russkiy arkhiv. 8. pp. 483-495.

12. Aronson, M. \& Reyser, S. (2001) Literaturnye kruzhki i salony [Literary circles and salons]. Moscow: Agraf.

13. Zhukovsky, V.A. \& Elagina A.P. (2009) Perepiska V.A. Zhukovskogo i A.P. Yelaginoy. 1813-1852 [Correspondence between V.A. Zhukovsky and A.P. Elagina. 1813-1852]. Moscow: Yazyki slavyanskoy kul'tury. 
14. Nikonova, N.E. (2010) V.A. Zhukovsky's correspondence with K. von Seidlitz: The Russian-German dialogue. Vestnik Tomskogo gosudarstvennogo universiteta - Tomsk State University Journal. 330. pp. 20-27. (In Russian).

15. Elagina, E.I. (2005) Semeynaya khronika [Family Chronicle]. Rossiyskiy arkhiv: istoriya Otechestva v svidetel'stvakh i dokumentakh XVIII-XX vv. Vol. 14. pp. 271-323.

16. Zhukovsky, V.A. (n.d.) Pis'mo V.A. Zhukovskogo $k$ velikomu knyazyu Aleksandru Nikolaevichu [Letter of V.A. Zhukovsky to Grand Duke Alexander Nikolaevich]. Russian State Archive of Literature and Art. Fund 198. List 1. № 51.

17. Zhukovsky, V.A. (n.d.) Pis'mo V.A. Zhukovskogo k A.O. Smirnovoy [Letter from V.A. Zhukovsky to A.O. Smirnova]. Department of Manuscripts, The Gorky Institute of World Literature. № 21216.

18. Kirchner, C.M. (1907) Wörterbuch der Philosophischen Grundbegriffe [Dictionary of Basic Philosophical Concepts]. Leipzig: Verlag der Dürr'schen Buchhandlung. [Online] Available from: http://www.textlog.de/2061.html.

19. Sidneva, S.A. (2014) Reprezentatsiya kontsepta dolce far niente v russkoy lingvokul'ture [Representation of the concept dolce far niente in Russian linguistic culture]. Vestnik Moskovskogo universiteta. Seriya 19. Lingvistika i mezhkul'turnaya kommunikatsiya. 4. pp. 38-47.

20. Zhukovsky, V.A. (1885) Pis'mo V.A Zhukovskogo k A.M. Turgenevu [V.A. Zhukovsky's letter to A.M. Turgenev]. Russkaya starina. 48. pp. 428-431. 